\title{
Solo cantando estuviera: versitos de la sierra de Piura
}

\section{RESUMEN}

La presente investigación tuvo como objetivos comprender algunas características de las expresiones artísticas llamadas «versitos» en la cultura de los campesinos de la parte alta del distrito de Yamango, provincia de Morropón, en la sierra del departamento de Piura, Perú. Se aplicó el método de observación participante, lográndose recoger y clasificar 212 cuartetas octosílabas cantadas en las fiestas locales y familiares. Esos «versitos», compuestos por ellos mismos o aprendidos en sus viajes a diversos lugares, son cantados en sus fiestas o recitados en la vida cotidiana, Son similares a las "pechadas» de la sierra de Cajamarca y cumananas de las zonas costeras de Piura y Lambayeque. Se refieren a las relaciones de familia, el amor de pareja, las dificultades de la vida, el desarraigo y la muerte.

PALABRAS CLAVE: Coplas, campesinos, género, expresión artística, síntesis cultural.

\section{"Solo cantando estuviera" (If I were singing along): small verses from Piura's highlands}

\begin{abstract}
This research aimed to understand some features of artistic expression called «rhymes» in the culture of the peasants from the top of the district of Yamango, Morropón province, in the Sierra of the department of Piura, Peru. Participant observation method was applied to collect and classify achieving 212 octosyllabic quatrains sung in local festivals and family. Those "rhymes», composed by themselves or learned on their trips to various places, are sung at their parties or recited in everyday life, they are similar to the "pechadas» of the Sierra of Cajamarca and cumananas of coastal zones of Piura and Lambayeque. Refer to family relationships, romantic love, the difficulties of life, uprooting and death.
\end{abstract}

KEYWORDS: Cultural synthesis, songs, peasants, artistic expression, gender. 


\section{Introducción}

$\mathbf{E}$ n la discusión sobre los problemas de transculturación y de asimilación cultural, en los cuales una sociedad impone su cultura sobre una población colonizada, se ha señalado que estos procesos son distintos a la integración o al mestizaje cultural, en los que la mezcla de culturas se realiza sin colonización y sin violencia. Abercrombie (1991) propone el término etnogénesis, para dar cuenta de la capacidad creativa de los pueblos que, tomando elementos de varias culturas crean la suya propia.

A esto mismo se refiere la etnomusicóloga Chalena Vásquez: "La síntesis cultural se entiende como el resultado de una o varias relaciones conflictivas y dinámicas; no son pues un simple acoplamiento o suma de elementos sino procesos de transformación resultante de dichas relaciones siempre en movimiento y en conflicto» (Vásquez, 2013: 14).

Para estudiar este problema tomamos una zona de intenso mestizaje y de débil integración a la economía urbana y moderna, por la escasez de tierra y otros recursos, por su producción poco mercantilizada y por no tener carretera. En ella, debemos tomar un elemento cultural para examinar hasta qué punto es producto de la mezcla de culturas, tanto en el contenido como en la forma. El recojo, análisis y publicación de estos productos culturales servirán para comprender mejor el mundo ideológico de esa población, a la vez que se le reconoce el gran aporte de su creatividad artística a la cultura regional y nacional.

El principal aporte al estudio y valorización de la cultura de la sierra piurana corresponde al gran investigador Justino Ramírez que en sus libros recogió no sólo los «versitos» o coplas, sino numerosas costumbres, leyendas y tradiciones ${ }^{1}$. Otros autores como Pedro Alarcón, León Barandiarán, José Maeda, Luis Rocca Torres y Wilman Ordóńez se han dedicado sobre todo a las cumananas de la costa norperuana. En todas estas recopilaciones se ha encontrado semejanzas y diferencias con los versitos recogidos por nosotros.

Agradecemos a todos los campesinos de Alto Yamango por su hospitalidad, amistosa colaboración y generosa información. Asimismo a la Central Peruana de Servicios y a su presidenta Elsa Fung, por la

1 Monografía de Huancabamba, Acuarelas Huancabambinas (tres volúmenes) y otras. oportunidad de trabajar en la zona de Yamango y otras de la región piurana, tan diversa como lo es el Perú.

\section{Contexto geográfico y social}

Los caseríos donde se hizo el estudio son los de Cajas, Confesionarios y Choco, situados en la parte alta y nor oriental del distrito de Yamango de la provincia piurana de Morropón (Piura, Perú). Su altitud fluctúa entre los 2,900 y 3,200 m.s.n.m., que —según los criterios de Nicole Bernex y Bruno Revesz (1987) — corresponden a la región natural de la Jalca, de clima frío pero de alta precipitación pluvial, que influye en su vegetación de bosque tropical húmedo, ya muy degradado.

Estos caseríos constituyeron hasta la década de 1960 el centro de la comunidad de Yamango, hegemonía perdida cuando en la zona de altitud media aumentó la producción de cultivos comerciales como el café, la cańa de azúcar y los frutales; construyéndose poco después la carretera hasta la actual capital distrital de Yamango. La creación del distrito en 1983 consolidó la hegemonía de la parte media.

En nuestra zona de estudio los cultivos predominantes son la papa, olluco, oca, arveja, habas, trigo, cebada y arracacha, complementados por ganado ovino, porcino y animales de corral, todo en un régimen de pequeña producción básicamente de autoconsumo. La fracción mercantil de su economía está constituida por el escaso ganado vacuno y el cultivo de ajos. En una clara muestra del modelo de «archipiélago vertical» de Murra, los campesinos medios de la jalca tienen también algunas parcelas más abajo, donde cultivan café, frutales y maíz. Otra fuente de ingresos monetarios son los salarios que obtienen al migrar a la costa y a las vecinas provincias de Jaén y San Ignacio.

La mano de obra proviene mayormente de la propia familia, pero también se practica la ayuda mutua, llamada "préstamo de fuerzas», así como la «minga» para la construcción de casas y otras tareas, en la cual numerosos pobladores trabajan gratis, aportando el dueño comida y bebida abundante. Termina en fiesta.

En la época autónoma, las partes baja y alta del distrito estuvieron sin duda entre las áreas de las culturas Vicús y Guayacuntos. Según los estudios de Anne Marie Hocquenghem (1981) los Guayacuntos se originaron de la gran etnia amazónica de los Jíbaros, cuya conquista costó mucho al Estado Inka. A unos 3 kilómetros al sur del caserío Choco se encuentran 
Gráfico 1. Ubicación de LA ZONA DE ESTUdio
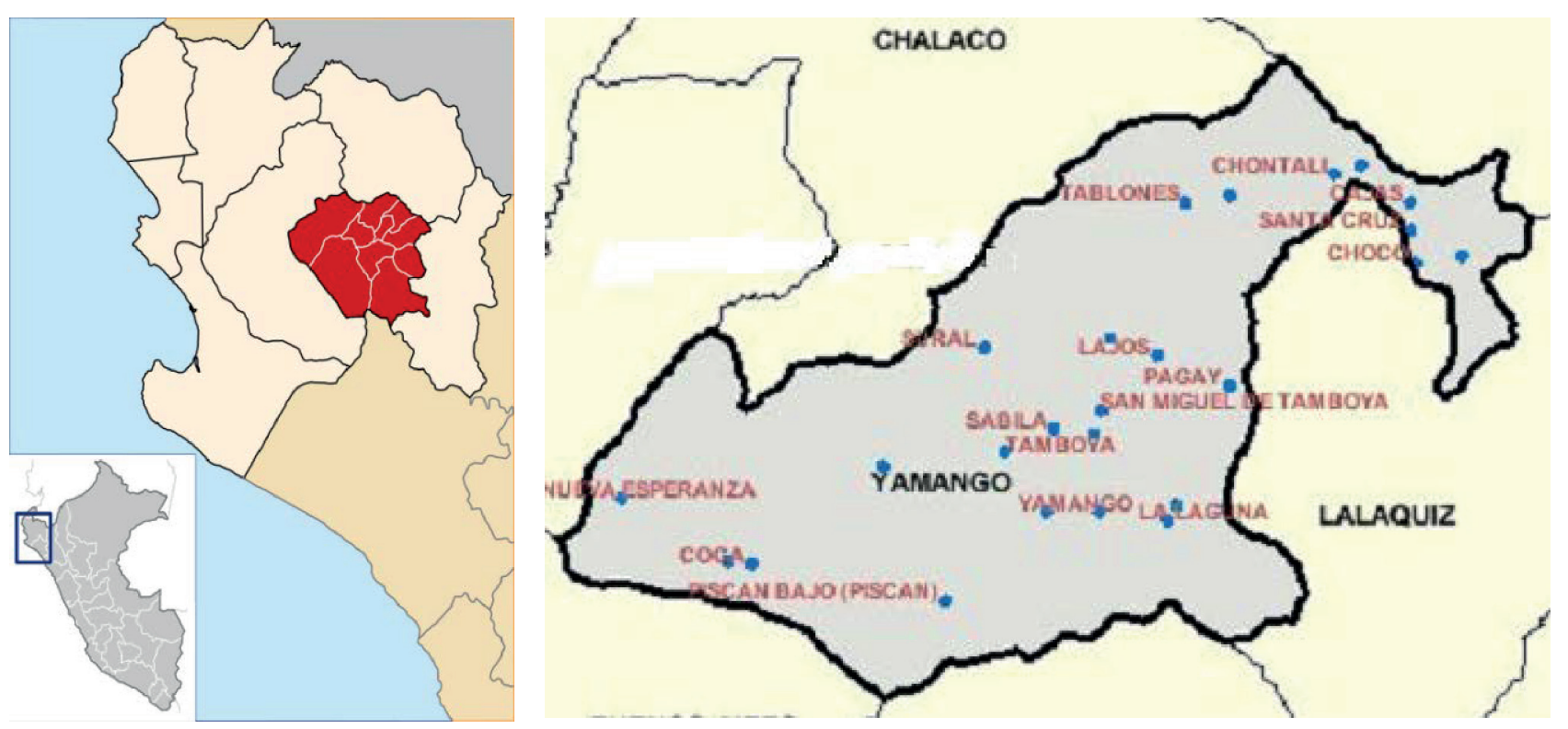

Provincia de Morropón y distrito de Yamango en la Región Piura (INEI 2003)

los restos de Caxas, de factura Inka. Y en toda la zona abundan restos arqueológicos no estudiados. Los campesinos se refieren a los habitantes de épocas antiguas como "los gentiles», afirmando que ellos, «como eran brujos, sabían que iba a venir nuestro señor Jesucristo. Entonces, rompieron sus ollas y se enterraron en cuevas» (Figueroa, 1989: 12).

Según los estudios del antropólogo Alejandro Diez Hurtado (1999: 36-40), toda esta zona es de un mestizaje andino-hispano mucho mayor al de la costa norteña. $Y$ en nuestra investigación, entre muchos apellidos de origen espańol, encontramos uno solo de origen andino (Huamán). Sin embargo, no obstante de que su idioma actual es el castellano, su cultura tiene claras raíces andinas, participando del cercano e influyente polo cultural de las lagunas de Las Huaringas (ver Polía Meconí, 1988), con curanderos de gran prestigio, creencia en los «apus», leyendas sobre «los Gentiles», etc.

Otra influencia cultural notable es la población afrodescendiente de algunos pueblos de la franja de costa colindante, como son los de Yapatera y Morropón (Rocca, 2011: 16, 385; Minedu, 2010: 8).

En las fiestas religiosas, se realiza una costumbre llamada "La Entrada», en la cual se representa una expedición al mando de un "capitán» y con un «negro» entre sus filas, grupo que en un primer contacto es recibido hostilmente por los pobladores hasta casi pelear, pero luego surge la acogida amable y empieza la fiesta. La música más escuchada por radio -y bailada en las fiestas - son los sanjuanitos y pasillos ecuatorianos.

Todos los varones, aunque sean pobres, son orgullosos de su independencia y su coraje. Se consideran "guapos» y cuando van a fiestas o salen a los pueblos llevan siempre al cinto un machete y un puñal en vainas de cuero repujado. Y cuando el aguardiente de caña (llamado "primera») altera los ánimos, sucede a veces que alguien, para demostrar que es el «más macho", arrastra la punta de su poncho por el suelo; y si alguien se lo pisa, los dos contendientes envuelven su poncho en el brazo izquierdo como defensa, peleando con el machete empuñado en la mano derecha. No se efectúan estas peleas en tumulto, sino siempre entre dos varones. En el ańo que vivimos en la zona, ocurrieron tres muertes a machete. Esta violencia es llamada lúdica y sería de duelo (desafío de individuo a individuo), competencia y pasatiempo, en búsqueda de prestigio (Diez Hurtado, 1999: 65-72).

$Y$ efectivamente no se utiliza para robar ni para asaltar. Al contrario, en la vida diaria los campesinos de la zona son trabajadores, honrados y pacíficos. Es la población más hospitalaria entre de las muchas estudiadas en el Perú. Si ven pasar a algún viajero al atardecer, lo llaman y le ofrecen alojamiento, diciéndole «Señor, ¿cómo va a viajar de noche? Descanse aquí y ya mañana sigue su camino». Si es de día, igualmente le dicen «venga, venga» le hacen sentar, le ofrecen algo de 
beber o comer y sólo después le preguntan «¿En qué lo puedo servir?». Adultos y niños en sus casas reciben a los que llegan o pasan cerca con la frase «venga, venga». Subrayamos que esta hospitalidad se dirige a todos, aún a los desconocidos.

Toda la población masculina viste con sombrero de paja, poncho de lana y llanques u ojotas. Las mujeres visten polleras de bayeta, ojotas o llanques y ponchos siempre negros. Encontramos sólo una joven de 17 años con poncho gris. Los zapatos se reservan para salir a la costa o a las ciudades.

\section{El trabajo de campo}

La investigación de campo se realizó de enero de 1987 a octubre de 1988, como parte adicional a la labor de promoción del desarrollo rural de la ONG Central Peruana de Servicios (Cepeser). El equipo total era de 3 personas, pero sólo el suscrito estaba encargado de la investigación social ${ }^{2}$, con el apoyo eventual del técnico Wilfredo Morocho. Se utilizó fundamentalmente el método cualitativo de la observación participante, tomando notas en libretas. Eventualmente, los mismos campesinos nos facilitaron algunas libretas o apuntes propios con canciones. Ya de regreso en Piura hicimos la transcripción, clasificación y análisis.
Sobre una población total de 147 hogares, si bien todos conocían y recitaban los «versitos», no todos tenían un repertorio abundante, por lo que las familias informantes fueron 12, muestra suficiente, pues encontramos varias repeticiones en el material recogido. Se llaman "cantistas» a los pobladores que entonan las cuartetas en las fiestas, generalmente con algo de alcohol en las venas. Entre ellos, Octavio Velasco, Bernabé Cruz, Efraín Román, Nico Román, Isaac Córdova, Marto Jiménez e Isaac Román. Los informantes principales fueron Edelmiro Moreto, Neftalí Mondragón, la «Mayor» Cela Román Huamán, Eufrasia Román Mondragón, Amalio García y Andrés García. Dos de ellos dijeron ser los autores de algunos de los versitos que nos dieron Otro dijo que componían en base a un viejo cancionero editado en Chiclayo.

\section{Resultados}

Presentamos: 114 de las 212 cuartetas recogidas, clasificadas en base a tres criterios: el tema, el sentimiento del emisor respecto al receptor $y$, finalmente, el género del emisor o autor.

TEMA 1. La relación con los padres

\begin{tabular}{|cc|}
\hline $\begin{array}{c}\text { En todos los pueblos he andado } \\
\text { preguntando por mi madre } \\
\text { sudando gotas de sangre } \\
\text { y aunque la busco ya es tarde }\end{array}$ & $\begin{array}{c}\text { Que falta me hace mi padre } \\
\text { que en un tiempo lo he perdido } \\
\text { sianque plata no me diera } \\
\text { seliz el que tiene madre }\end{array}$ \\
anda en el mundo gozando & Qué triste se pone el sol \\
y yo que no tengo a nadie & cuando se llega la tarde \\
ando en el mundo llorando & más triste me pongo yo \\
\hline
\end{tabular}

2 El tema encargado por la ONG era la organización económica. El tema presente fue iniciativa del suscrito y tuvo que hacerse como esfuerzo adicional al primero. 
TEMA 2.- El arraigo y el desarraigo

Si la zarza no me zarza

si el bejuco no me enrieda

si la muerte no me mata

he de volver a mi tierra

Ya me voy ya me estoy yendo

por el camino de las delicias

si Dios quiere volveré

o por lo pronto mis noticias
Desde mi tierra he salido

con dos determinaciones

la de volver a mi tierra

o quedarme en los panteones

En mi tierra que yo vivo

solo pampas y retoños

yo no me olvido del sitio

sino de los testimonios

\section{TEMA 3.- La tristeza, la pobreza}

El cielo está de luto

la luna de manto negro

las estrellas guardan duelo

para mí ya no hay consuelo

Soy sortijita de oro

soy sortijita de cobre

por todo merecería

solamente yo por pobre

A la experiencia la he comprado

por no haberla conocido

ahora la vuelvo a vender

basta con lo que me ha sucedido
Las estrellas en el cielo

las cuento y no estaba cabal

no habrá suerte tan bandida

como la mía tan fatal

Ha llegado la fiestita

la fiestita del florecer

qué triste ha sido ser pobre

y no poder merecer

Yo quisiera ser polvito

para que me lleve el viento

si me llegara la muerte

se acabará el sentimiento

Por qué te dueblas cuchillo

sabiendo que sos de acero

así se dueblan los hombres

cuando no tienen dinero

TEMA 4.- Guapería, machismo

Yo soy el gallito pinto

con la pluma en oreja

que cuando sale a pelear

no espera que haya coteja
Desta banda a la otra banda

me corren como a un oso

no me corren por celoso

sino por facineroso 
Así es la vida del borracho no habrá suerte más fatal anda tomando con su plata y todavía lo miran mal

A todos los santos les pido y a las ánimas benditas que dos amores que tengo se quieran como hermanitas

Tres oficios he aprendido ninguno puedo oficiar de tres amores que tengo ninguna la puedo dejar
La malva con ser malva en cualquier peña florece el hombre que es namorado en cualquier cama amanece

Me llaman el clavel coronado porque me vivo serenando las muchachas me aborrecen porque las vivo engañando

El gavilán en el campo se come la carne cruda así me la como yo cuando la suerte me ayuda

TEMA 5.- Amor, enamoramiento

Desde mi tierra he salido

en busca de un amor celeste

ando buscando un amorcito

aunque la vida me cueste

Bejuquito de la montaña que crece y no florece qué será de mi amorcito que lo llamo y no aparece

Como fuera que tu amor conmigo fuera la suerte para tenerte en mi abrigo hasta que venga la muerte

La flor de la tuna blanca la cogí por más madura un amor cuando se quiere con los ojos se saluda
Rosas blancas y amarillas

entre'n medio de mis jardines

yo quisiera un amorcito

y tenerlo hasta los fines

De mi casa pa'bajito

tengo una planta de mango

puedo perder la vida

por unita de Yamango

A tu puerta yo he venido a cantarte esta canción y entregarte mi amor querido

de mi pecho el corazón

Frijolito colorado

sembrado de trecho en trecho el tratito que hemos hecho ya lo tengo aquí en mi pecho 


\begin{tabular}{|c|c|}
\hline La flor de la manzanilla & Florcita de albahaca blanca \\
\hline también tiene su alegría & déjala para semillita \\
\hline si has nacido para ser miya & negrita si tú me quieres \\
\hline miya has de ser algún día & quedamos pa qué diíta \\
\hline Qué bonitos son los lirios & Qué bonita muchachita \\
\hline cuando están todos floridos & con su alforjita marcada \\
\hline qué bonitos tus ojitos & de poncho bien lavadito \\
\hline que los tienes escondidos & lujosita y bien peinada \\
\hline En esos tus lindos ojos & Qué bonita muchachita \\
\hline he puesto mi amor sincero & tracitas de jovencita \\
\hline para que creas y veas & ella misma lo demuestra \\
\hline que en realidad yo te quiero & tracitas de halagûeñita \\
\hline Frijolito colorado & Quisiera subir al cielo \\
\hline sembrado el dos de mayo & donde suben los aviones \\
\hline en tus prendas yo me muero & pa' contarle a mi amorcito \\
\hline y en tus brazos me desmayo & cuáles son mis aficiones \\
\hline Te voy a mandar una cartita & Cómo quisiera tener \\
\hline escrita con letras verdes & la dicha del picaflor \\
\hline allí te mando a decir & para chuparme cholita \\
\hline que sólo de mí te acuerdes & la dulzura de tu amor \\
\hline Qué bonita flor morada & Dame la mano negrita \\
\hline florcita de chamelico & para machucarte un dedo \\
\hline hasta polillita me hiciera & aunque gozarte no puedo \\
\hline pa' besarte en tu piquito & pero me llevo el consuelo \\
\hline El besito que me diste & Una estrella se ha perdido \\
\hline hasta ahora me está durando & que en el cielo no aparece \\
\hline la dulzura de esa boquita & en las puertas de tu casa \\
\hline la vida me está quitando & paloma blanca parece \\
\hline
\end{tabular}




\begin{tabular}{|c|c|}
\hline \multicolumn{2}{|c|}{ TEMA 6.- Actitud despectiva en general } \\
\hline Ahí te mando una cartita & Decías que sabes querer \\
\hline escrita en hoja de palta & ha sido palanganada \\
\hline allí te mando a decir & cuando sabes que me alejo \\
\hline que amores no me hacen falta & ahí sigues con la manada \\
\hline Cuchillito cachita blanca & Dices que no me quieres \\
\hline contrapesado en balanza & por una duda por una duda \\
\hline cuidadito cuidadito & yo tampoco te quiero \\
\hline que ahora ya no hay confianza & porque eres cara de ruda \\
\hline De mi casa pa'llacito & Pensaste hacerme fieros \\
\hline tengo una olla cenicera & por irte a brazos ajenos \\
\hline acércate pa'cacito & tú mismo te los hiciste \\
\hline pa' sacarte la sonsera & para nada te echo de menos \\
\hline \\
\hline \multicolumn{2}{|c|}{ media por de afuera } \\
\hline \multicolumn{2}{|c|}{ en la calle te dejé } \\
\hline \multicolumn{2}{|c|}{ pa' que te recoja cualquiera } \\
\hline
\end{tabular}

TEMA 7.- Actitud despectiva de varones

\begin{tabular}{|c|c|}
\hline Hoy te mando una cartita & Bien dicen que'n esta vida \\
\hline escrita con mis saludos & la cosas son al revés \\
\hline tú siempre te enamoras & lo mismo que unas mujeres \\
\hline de los hombres más platudos & amantes al interés \\
\hline De mi casa pa'bajito & La piedra que mucho rueda \\
\hline hay una planta de zapallo & no sirve para cemento \\
\hline las mujeres de este tiempo & una muchacha muy bailadora \\
\hline se arreglan más que caballo* & no sirve pa' casamiento \\
\hline Yo no quiero ser casado & Allí amigo le aconsejo \\
\hline con una falsa mujer & que no quiera como yo \\
\hline porque es una vida amarga & la cholita que he tenido \\
\hline muy mala para querer & fue muy mala y me dejó \\
\hline
\end{tabular}

* Los caballos son muy apreciados y sus aperos son adornados con monedas de plata. 
Por arriba por ese cerro

me vide un palo choposo

ya te conozco chinita

con tu ponchito motoso

A todos andas contando

que tienes mantas bordadas

y cada vez que voy a tu cama

te encuentro piernas peladas
El ponchito que me has hecho

tejidito en el telar

de merinito lo has hecho

haragana por no hilar

Las mujeres de este tiempo

son como la cocha blanca

con el poncho de dos hebras

y la pollera de retranca

TEMA 8.- Actitud despectiva de mujeres

Los muchachos de este tiempo

son como la tusa quemada

andan de cantina en cantina

y el alma más condenada

Los muchachos de este tiempo

son como el olluco poroto

amantes a enamorar

y andan con el pantalón roto

Quiero un amorcito de lejos

pa' que tenga que caminar

porque estos de mi tierra

más se la llevan en hablar

Ya me has dicho que te casas

casadito te he de ver

en la puerta de la iglesia

como escoba de barrer

Vestidito me has ofrecido

no le supe la color

seguro que fue carito

por eso te dio dolor
Los muchachos de este tiempo

son como el mote lejiado

apenas tienen quince ańos

y andan con el cańacito fiado

Estuve criando un perrito

con la leche del cordoncillo

nombrecito le iba cayendo

palangana sin calzoncillo

Dicen que la ruda es amarga

y yo te la hice beber

para que sepas ser hombre

y respetar a una mujer

Canta canta burrioncito

en el cogollo de esa altamisa

ofreciendo cincuenta libras

mejor déjalas pa' tu camisa

Qué te pega mosquito negro

que tanto andas por aquí

aunque yo pobre negrita

no me ofrezco para ti 


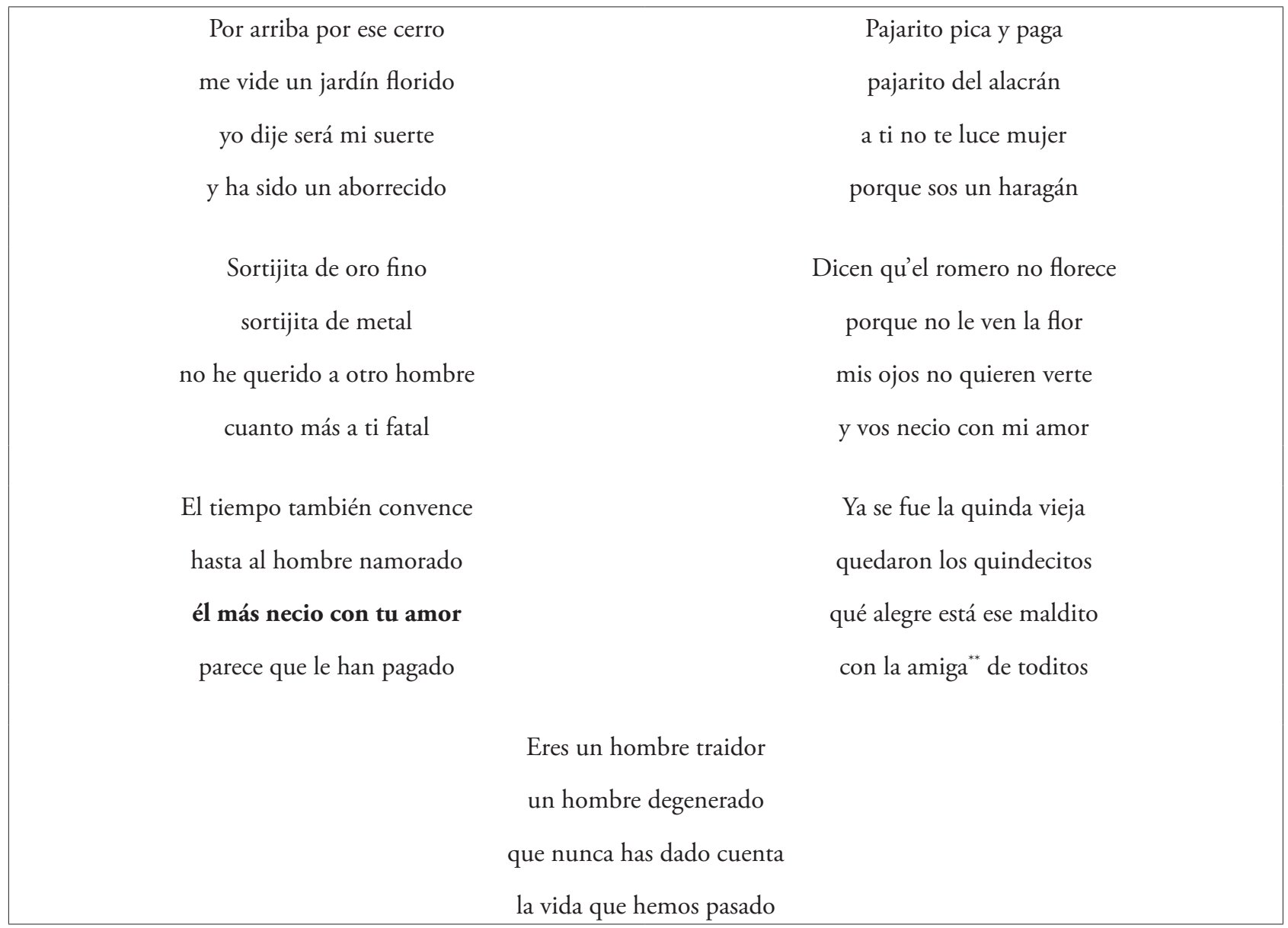

TEMA 8.- Las penas del amor

\begin{tabular}{|cc|}
\hline $\begin{array}{c}\text { La lista de tu ponchito } \\
\text { tiene verde mormorè } \\
\text { el amorcito que yo tuve } \\
\text { fue poquito y se me fue }\end{array}$ & $\begin{array}{c}\text { Ramita de sauce verde } \\
\text { cogollito de overal }\end{array}$ \\
cómo quieres que te quiera & si el tiempo no da lugar \\
Romerito chiquitito & Ahí te dejo un romero \\
quén verano te marchitaste & anda cógete un gajito \\
cómo no me marchito yo & y si ya no me has querido \\
con el cuento que me engańaste & muchas gracias tu amorcito \\
Clavelito colorado & A la flor de la tunita \\
que te vives amarchitando & la dejé por mala flor \\
esperemos el invierno & ahora que la veo bonita \\
pa’ que veas tu desengańo & me da pena y dolor \\
\hline
\end{tabular}

* En el lenguaje de la zona, amiga significa concubina o amante. Para significar lo que en el castellano corriente se expresa como "mi amigo» o "mi amiga», en la zona dicen: "mi amistad» 
Ya salió el sol enlutado

y el río no quiere correr

si mi amor fue aborrecido

ya no le he de ver golver

Yo no sé qué amor es este

que no puedo comprender

que hasta el sueño se me quita

y las ganas de comer

Si supiera que en el cielo

se ha vendido un corazón

me fuera y comprara unito

que’l mío está en una prisión

El destino se arrepiente

de haber nacido en el campo

así me arrepiento yo

de haberte querido tanto

Abre puertas y ventanas

como de favor te pido

pa’ que escuches esta canción

de tu amante aborrecido

Hay he hecho la diligencia

para podernos separar

qué remedio me habrás hecho

pa' no poderte olvidar

Guacaquita tejedora

que te tejes en el aire

no es posible señorita

que me dejes en desaire

\section{Hasta mi guitarra llora \\ y se queja de dolor \\ así mismo lloro yo}

por no conseguir tu amor

Mapolita colorada

corazoncito amarillo

cómo quieres que te quiera

si no me muestras carińo

Ya no llores corazón

que ella no ha de volver

duele el alma destrozada

y el ver tanto padecer

Cada vez que paso y miro

donde solíamos estar

mi corazón tiene pena

$\mathrm{y}$ mis ojos quieren llorar

Qué bonito corre el agua

por debajo de ese cautivo

así corre mi amor

sin saber lo efectivo

De mi casa pa'llacito

tengo una mata de llatan

la vida la he de perder

por una hija de ermitaño

Una madeja de hilo

se me fue ya deshilando

un amorcito que yo tuve

también se fue terminando 
TEMA 10.- Celos en el amor

\begin{tabular}{|cc|}
\hline $\begin{array}{c}\text { Un día que tú me hablaste } \\
\text { yo estaba resentido } \\
\text { porque me has hecho traiciones } \\
\text { con otro nuevo querido }\end{array}$ & $\begin{array}{c}\text { Un día llegué a tu casa } \\
\text { y cambiaste de color }\end{array}$ \\
Dicen que el amor espina que me has cambiado \\
el palo es el espinoso \\
mi corazón es el firme & yo necio con tu amor \\
\cline { 2 - 2 } y el tuyo es el engañoso & He sabido por noticias \\
Ojos negros de mi vida & que vives averiguando \\
a quién lo estarán mirando & no importa que averigües \\
¿será firme tu cariño & y no me vivas celando \\
o me estarás engańando? & Tú dices que sí me quieres \\
& yo digo que así será \\
\hline
\end{tabular}

TEMA 11.- Rechazo de los chismes

Cambiara una noche clara

por una que venga oscura

la gente es tan sabedora

luego luego se asegura

Congonita chiquitita

qué hojita pa’ diferente

casémonos de una vez

para que no hable la gente

Por dentro por asomar

sale una perica agrora

le voy a quemar el pico

por chismosa y habladora

Po’ allá arriba por ese cerro

baja un buitre de copete

estando bien con mis padres

viene un perro y se entromete
Cuatro palomas volaron

por sobre la carretera

el tiempo no dice nada

sino la gente novelera

Vuela vuela golondrina

por debajo de ese convento

por ahí me voy a ir

aburrido de tanto cuento

Por esa ladera me estoy yendo

perritos voy encontrando

por culpa de esos perritos

qué cuentitos me irán sacando

Yo soy la yerbita amarga

que amargo a toda la gente

siempre viven desdorando

cuando yo no estoy presente 


\section{Ándate pues resolviendo}

pa' irnos a otro lugar

que aquí no nos pueden ver

ni nos podemos estar

\section{TEMA 12.- El valor de la soltería}

Alto en el cielo está la luna

más adentro el lucero

para el hombre que es soltero

en cualquier tierra he de merecer

Cuchillito cacha 'e plata

comprado para mis venganzas

mientras viva solterito

no pierdo las esperanzas

Ahí te mando una carta

escrita con dos tinteros

no tengas miedo amorcito

que los dos somos solteros
Sortijita de oro fino

que en el mar se me cayó

prenda de muchacha libre

solterita como yo

Yo soy la naranja entera

Yo soy la media naranja

yo soy la mujer soltera

pero no quiero a cualquiera

Por allá por La Victoria

los enseñas con el dedo

si es casado no lo almito

si es soltero, luego, luego

\section{TEMA 13 .- Consejos sobre el matrimonio}

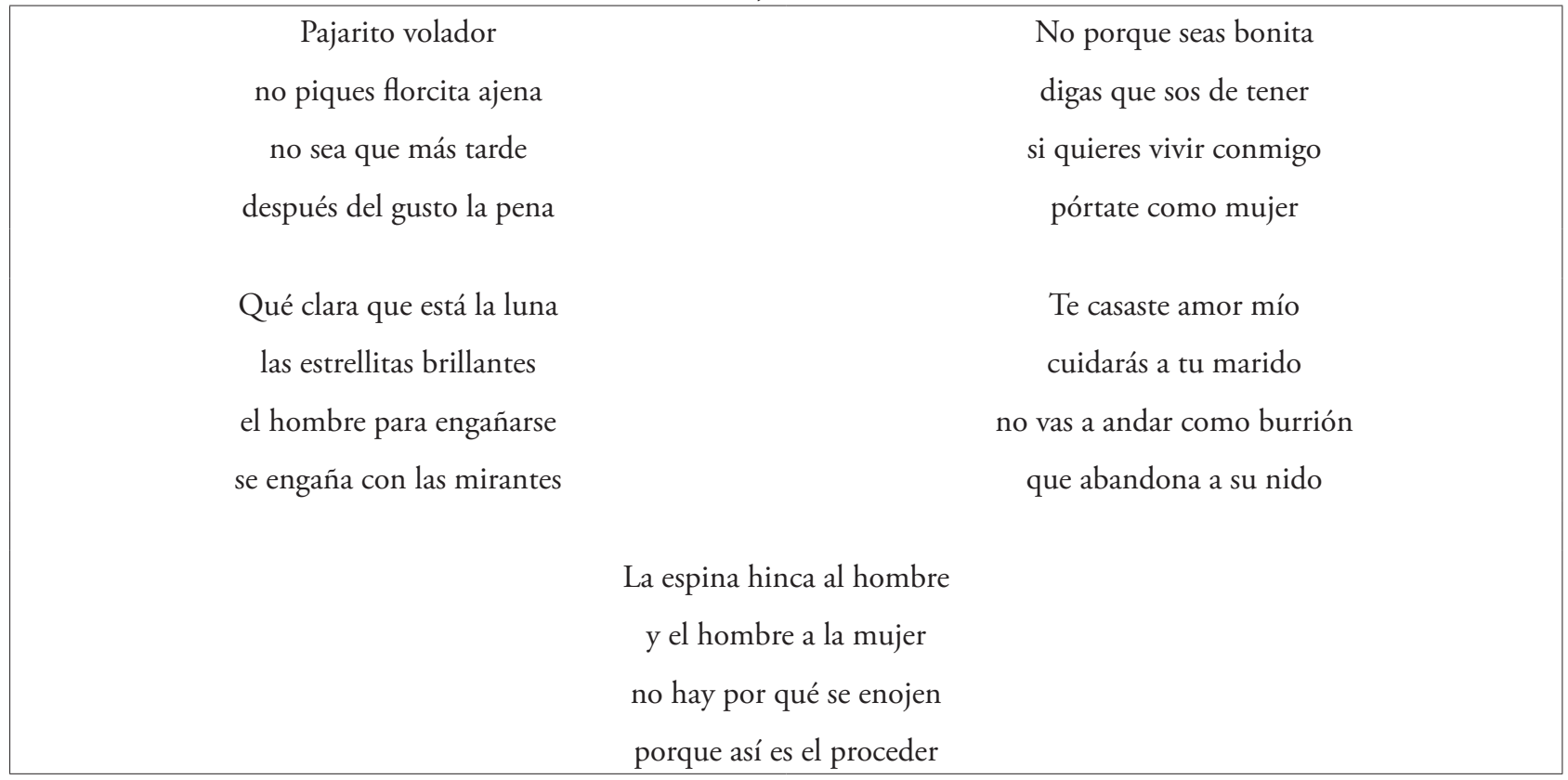


TEMA 14.- La alegría de amar y cantar

\begin{tabular}{|cc|}
\hline $\begin{array}{c}\text { Quisiera ser estrellita } \\
\text { para prestar claridad } \\
\text { de todo me encuentro bien } \\
\text { contento y felicidad }\end{array}$ & $\begin{array}{c}\text { Por demás si me aborrecen } \\
\text { siempre yo vivo queriendo }\end{array}$ \\
con mis bonitas caricias \\
Versitos quiero escoger & siempre yo vivo riendo \\
los más bonitos también & Así lo digo y así lo canto \\
como amores que contar & así es mi procedimiento \\
los que se cumplen recién & sólo cantando estuviera \\
\hline
\end{tabular}

\section{Discusión}

En este conjunto de "versitos» se advierte el mestizaje en la combinación de la forma de coplas (cuartetas octosílabas), indudablemente aportada por la cultura hispana. En cuanto al tono del canto en las fiestas se aproxima al «triste» ${ }^{4}$, que tendría ascendencia en los harawi andinos.

Un tercer componente es la cultura afroperuana, entendida como etnogénesis colonial y republicana de la población esclavizada. Desde Nicomedes Santa Cruz hasta Chalena Vásquez (2013a: 2) señalan esta impronta cultural en la cumanana, cuyo significado en la lengua africana quicongo sería "canto en contrapunto». A esto debe sumarse el frecuente uso del vocativo "negrita» en los versitos de Alto Yamango, zona en la cual no se encuentran afrodescendientes y predomina ampliamente el genotipo de piel clara. Es posible, pues, que esos versos hayan sido aprendidos en las zonas costeńas donde sí hay cultura afroperuana.

No es posible por ahora conocer desde cuando se cantan y recitan los versitos o coplas en Alto Yamango, aunque los pobladores de mayor edad dijeron que ya sus abuelos los practicaban. Para la costa piurana, López Albújar (1928) las atribuye ya al siglo XIx. Justino Ramírez no rastrea la historia de las coplas, pero las que consigna (1960 y 1970: 22, 93) eran vigentes en Huancabamba a mediados del siglo xx. Pina Zúńiga (1984: 67-72) recoge coplas costeñas de poco después.

Los versitos consignados dan cuenta también de un fluido intercambio cultural en toda la costa norperuana y ecuatoriana. En la amplia recopilación de coplas de

4 Chalena Vásquez anota que el triste es un «tipo de yaraví de la costa norte» (2013: 27) la cultura montubia del Ecuador (Ordoñez 2004) se encuentran numerosas cuartetas iguales o similares a las transcritas por nosotros líneas atrás. Se encuentran también similitudes con las cuartetas consignadas por Luis Rocca (1985 y 2010: 387-390). Y también con las transcritas por Pedro Delgado (1985: 182-191 y 1986: 126-166). Por la falta de fuentes escritas, es imposible conocer el origen de las coplas y en qué dirección geográfica han viajado, pero se puede considerar como posibles determinantes de esa fluidez cultural las migraciones y la similitud de experiencias populares compartidas entre campesinos y jornaleros de zonas diferentes pero similares en la situación subordinada de las clases populares.

En cuanto a la temática de las coplas, sin duda, el tema predominante es el amor de pareja, el erotismo y la vida de familia, seguido de las reflexiones sobre la dureza de la vida en el campo, la identidad local y la ideología de la "guapería» y el machismo. Aunque esto último está matizado por la activa participación de las mujeres, que contraponen ingeniosamente sus propios puntos de vista y su rechazo al papel pasivo que les asignan los varones, así como expresan su rechazo a los chismes. (Ver temas 8 y 11 de los versitos). Esto está en correspondencia con una de las funciones de las rondas campesinas, que es el de prevenir y castigar los chismes.

Aquí parece apuntar una diferencia, pues en las cumananas de la costa norperuana y en sus intérpretes no se nota de presencia de mujeres en roles activos, mientras en Alto Yamango y en la cultura montubia del Ecuador (Ordońez, 2004: 52-65) esa presencia y expresión son minoritarias pero activas. Habría que comparar también esto con las coplas de Cajamarca 
cantadas por las pallas (niños y mujeres jóvenes), en las festividades religiosas de esa región.

Otro aspecto importante - ya advertido por varios autores - es la abundancia de referencias a la naturaleza (flora y fauna, cerros, pampas, ríos, clima), a la agricultura (cultivos, trabajo), a los productos de la labor humana (caminos, pueblos, viviendas, herramientas, telares y tejidos); y a las relaciones sociales (pobreza, injusticias). Y esto es una de las pruebas de lo que Chalena Vásquez llama síntesis cultural y Abercrombie llama etnogénesis (1991). Es decir, al igual que todos los pueblos, los campesinos de Alto Yamango crean y recrean su cultura, la transforman y actualizan, con su experiencia viva y con los materiales aportados por la tradición y los intercambios culturales.

\section{Conclusiones}

Los versitos recitados y cantados por los pobladores de Alto Yamango constituyen la confluencia de las tradiciones culturales andina, hispana y afroperuana, por lo que puede estudiarse esta práctica cultural dentro de las expresiones de etnogénesis y de síntesis cultural.

En su forma, en su temática y en sus funciones se emparenten tanto con la cumanana de la costa norperuana, como con las pechadas de Cajamarca y el amorfino del Ecuador. Su producción combina la creación local con lo aprendido en las migraciones de la población a diversas regiones contiguas. En este caso, sus contenidos son adaptados al lenguaje, experiencias y motivos de la zona, en función de los problemas y sentimientos de la población local.

El lenguaje de estos versitos tiene muchos referentes locales, de la naturaleza, de la agricultura y el trabajo, de la actividad textil y doméstica tanto de varones como de mujeres.

Sus temas fundamentales son la identidad local (expresada en los sentimientos de desarraigo), la familia, la pobreza y la suerte, la guapería, el amor de pareja y el erotismo, el matrimonio, la actitud despectiva o de competencia entre varones y mujeres, el rechazo a los chismes y la alegría de vivir, expresada en la alegría de amar y cantar.

A diferencia de la tradición de la cumananas de la Costa, en su producción las mujeres tienen un rol NO mayoritario pero sí activo, contraponiendo al machismo una aspiración a la independencia y a la equidad de género.

\section{Referencias bibliográficas}

Abercrombie, Thomas (1991). "Articulación doble y etnogénesis.» En Reproducción y transformación de las sociedades andinas, siglos XVI-XX. Quito: Ed. Moreno and Salomón.

Alarcón, Pedro (1992). Cumananas piuranas. Lima: Lluvia Editores.

Bernex, Nicole y Bruno Revesz (1988). Atlas regional de Piura. Lima: Ed. CIPCA-PUCP.

Delgado Rosado, Pedro (1995). "Cocina, cultura e identidad lambayecanas». En Utopía Norteña No 2. Lambayeque: Universidad Nacional Pedro Ruiz Gallo.

Delgado Rosado, Pedro (1996). «Música, poesía e identidad popular en Lambayeque». En Utopía Norteña No 3. Lambayeque: Universidad Nacional Pedro Ruiz Gallo.

Diez Hurtado, Alejandro (1999). Comunidades mestizas. Lima: Ed. PUCP-CIPCA.

Diez Hurtado, Alejandro (1994). «Transformaciones sociales en la sierra de Piura». En El Problema Agrario en Debate Tomo. 5: 154-174. Lima: SEPIA.

Figueroa Luna, Guillermo (1988). «Conflictos por la tierra y cohesión comunal en Alto Yamango». Apuntes de Campo No 8. Piura: CEPESER.

Figueroa Luna, Guillermo (1989). «Los restos arqueológicos de Caxas en la sierra de Piura». Ponencia al $X$ Congreso del Hombre y la Cultura Andina. Trujillo.

Guffroy, Jean, Peter Kaulicke y Krzysztof Makowski (1991). "La prehistoria del departamento de Piura». En Boletín del IFEA No 18 http://www.ifeanet.org/ publicaciones/boletines/18(2)/117.pdf

Hocquenghem, Anne Marie (1990). Los guayacuntus de Caxas. Piura: Ed. IFEA-CIPCA.

INEI (1993). Distrito de Yamango Instituto Nacional de Estadística e Informática, Lima http://pe.images.search. yahoo.com/images/view;

León Barandiarán, Augusto (1979). «Las cumananas». La Industria 29.10.1979, Chiclayo.

Maeda, José (1987). «La Cumanana: ¿Tradición negra o Indígena?» Diario La Industria Suplemento Dominical 20,12.1987, Chiclayo.

MaEda, José (2011). Cumanana y triste: tradición prehispánica Muchik. http://www.monografias.com/trabajos66/ cumanana-triste/cumanana-triste.shtml 
Minedu (1910). Somos afrodescendientes, somos Perú. Lima: Ed. de Ministerio de Educación.

Morocho, Wilfredo (1988). «Celebración navideña en Cajas». En Apuntes de Campo No 8. Piura: CEPESER.

Ordoñez Iturralde, Wilman (2004). Amorfino, canto mayor del montubio. Ecuador: Ed. Shamán.

Polía Meconí, Mario (1995). Las lagunas de los encantos. Piura: Ed. CEPESER.

Ramírez, Justino (1966). Monografia de Huancabamba. Su historia, su geografía, su folklore. Lima: Imprenta del Ministerio de Hacienda.

Ramírez, Justino (1970). Acuarelas huancabambinas. Vol. I. Piura: Imprenta La Región.

Rocca Torres, Luis (1985). La otra historia de Zaña. Lima: Instituto de Apoyo Agrario.
Rocca Torres, Luis (2010). Herencia de esclavos. Lima: Ed. CEDET.

Sevilla Exebio, César (2004). Del folklore ferreñafano. Ferreñafe: Ed. Conea.

Vásquez, Chalena (2013). Historia de la música en el Perú. PUCP - Ministerio de Educación, Lima. http://www. chalenavasquez.com/pdf/historiamusica_ministerio.pdf

Vásquez, Chalena (2013a). Canto en contrapunto. http:// www.chalenavasquez.com/pdf/Cumanana.pdf

Vásquez, Chalena (2013b). La Costa: Presencia africana en la costa peruana. http://www.chalenavasquez.com/pdf/ costa_\%20Chalena_Vasquez.pdf

ZúNiga, Pina (1984). Música y danzas folklóricas de Piura. Piura: Universidad de Piura - INC. 